\title{
ANALISIS KESANTUNAN IMPERATIF BAHASA INDONESIA DALAM TEKS PIDATO SISWA KELAS IX SMP NEGERI 1 CIDADAP KABUPATEN SUKABUMI
}

\author{
Yanyan \\ Universitas Muhamadiyah Sukabumi \\ yanyandeyan2510@gmail.com
}

\begin{abstract}
Abstrak. Penelitian ini bertujuan untuk mengetahui dan mengidentifikasi penggunaan kalimat yang menunjukan kesantunan imperatif ajakan, permintaan, dan suruhan dalam teks pidato siswa kelas IX SMP Negeri 1 Cidadap. Jenis penelitian ini adalah jenis kualitatif. Data dalam penelitian ini adalah wujud atau bentuk kalimat kesantunan imperatif yang terdapat dalam teks pidato yang di tulis siswa kelas IX SMP Negeri 1 Cidadap. Adapun Metode yang digunakan dalam penelitian ini adalah metode simak dengan beberapa teknik, pertama yaitu teknik simak bebas cakap dan yang kedua adalah teknik catat. Hasil dari penelitian ini dan analisis yang dilakukan, terhadap teks pidato siswa kelas IX SMP Negeri 1 Cidadap Tahun Pelajaran 2019/2020 yang berjumlah 10 naskah pidato dan 21 data yaitu: Sebanyak 13(tiga belas) data menunjukan kesantunan imperatif ajakan, sebanyak 7 (tujuh) data menunjukan kesantunan imperatif permintaan, dan sebanyak 1 (satu) data menunjukan kesantunan imperatif suruhan. Berdasarkan hasil tersebut dapat disimpulkan bahwa siswa kelas IX SMP Negeri 1 Cidadap Tahun Pelajaran 2019/2020 lebih banyak menggunakan kalimat kesantunan imperatif ajakan dibandingkan dengan kalimat kesantunan permintaan maupun kalimat kesantunan suruhan.
\end{abstract}

Kata kunci : Kesantunan, imperatif, teks pidato

Abstract. This research aims to identify and use the term to identify and use the term to identify and use the sentence to identify the use and identification of the sentence imperative invitation in speech text, politeness of the request, politeness of the messengers of class IX students of SMP Negeri 1 Cidadap. The data source in this study was the speech text of grade IX students of SMP Negeri 1 Cidadap. The method used in this study is the method of listening with several techniques, the first is the technique of free speech and the second is the note-taking technique. Which amounted to 10 speech scripts and 21 data, namely: A total of 13 (thirteen) data shows the courtesy of the invitation imperative, as many as 7 (seven) data indicate the imperative politeness of the request, and as much as 1 (one) data indicates the imperative politeness of the order. Based on these results it can be concluded that grade IX students of SMP Negeri 1 Cidadap in the 2019/2020 Academic Year use more sentences of invitation imperative politeness than those of request politeness sentences or sent politeness sentences.

Keywords:Politeness, imperative, speechtext

\section{PENDAHULUAN}

Bahasa adalah salah satu alat atau media untuk komunikasi antara orang yang satu dengan lainnya. Sebagai manusia tentunya hal ini merupakan hal yang sangat penting dalam kehidupannya, karena sebagai makhluk sosial manusia tidak bisa sendirian dalam memenuhi segala kebutuhan kehidupannya antara yang satu dengan lainnya saling ketergantungan. Manusia hidup secara berkelompok, baik kelompok kecil (keluarga) atau kelompok besar (masyarakat). Oleh 


\section{Yanyan \\ ANALISIS KESANTUNAN IMPERATIF BAHASA INDONESIA \\ DALAM TEKS PIDATO SISWA KELAS IX SMP NEGERI 1 CIDADAP \\ KABUPATEN SUKABUMI}

sebab itu komunikasi menjadi sangat penting adanya, melalui berkomunikasi maka pesan-pesan atau informasiinformasi yang ingin disampaikan dari orang yang satu kepada yang lainnya akan berjalan dengan lancar apabila penggunaan bahasa yang digunakan baik dan tentunya bisa diterima dan dipahami. Jika hal yang demikian terjadi maka maksud dan tujuan kedua belah pihak akan tercapai.

Bahasa sangat penting peranannya dalam kehidupan manusia, oleh karena itu pembelajaran bahasa sudah mulai diperkenalkan sejak manusia mulai bisa berbicara. Sejak kecil penggunaan bahasa sudah mulai diarahkan dalam berkomunikasi bagaimana bahasa yang baik dan mana bahasa yang tidak baik.

Dalam dunia pendidikan pembelajaran bahasa merupakan hal yang sangat vital, karena bahasa merupakan media dalam menyampaikan proses pembelajaran. Penggunaan bahasa yang tepat tentunya akan sangat membantu dan memudahkan dalam memahami dan menyerap ilmu pengetahuan di sekolah, namun sebaliknya materi pembelajaran apapun jika dalam penyampaian proses pembelajarannya menggunakan bahasa yang kurang tepat atau tidak sesuai tentunya materi pembelajaran akan menemukan kesulitan untuk dapat dimengerti dan dipahami. Oleh sebab itu pembelajaran bahasa di semua jenjang pendidikan mulai sekolah dasar sampai perguruan tinggi selalu diajarkan.

Dalam berkomunikasi sehari-hari pada umumnya berbahasa ada dua macam bentuk, yaitu pertama bentuk lisan dan yang kedua bentuk tulisan. Bentuk lisan dapat dikatakan bentuk langsung, artinya dalam berkomunikasi pembicara langsung bertemu atau tatap muka dengan pendengarnya tanpa adanya media atau apapun yang dijadikan perantara. Sementara bentuk tulisan dapat disebut tidak langsung, artinya dalam berkomunikasi pembicara tidak bertemu atau tatap muka dengan pendengar melainkan melalui alat atau media perantara.

Salah satu contoh dari bahasa bentuk lisan adalah pidato. Pidato merupakan berbicara atau berbahasa langsung dalam menyampaikan pesan dan informasi kepada pendengar atau orang yang dituju. Untuk itu maka bahasa yang disampaikan harus mudah di mengerti dan dipahami. Bahasa yang baik dan santun merupakan keharusan dalam berpidato, apalagi didalamnya memuat sebuah pesan atau perintah agar pendengar melakukan hal yang diharapkan. Dengan bahasa yang santun akan membuat pendengar atau khalayak umum merasa nyaman dan tidak merasa tersinggung, bahkan bisa saja akan merasa senang yang akhirnya mereka mau melakukan hal yang diharapkan oleh si pembicara.

Jika kita perhatikan dalam pergaulan sehari-hari kesantunan dan etika berbahasa menjadi sebuah tuntutan baik bagi penutur atau pun mitra tutur, keduanya harus sama-sama saling menghargai dan menghormati, agar pembicaraan atau berkomunikasi yang dilakukan tidak saling merugikan. Karena terkadang dengan kurangnya pengetahuan tentang etika berbahasa dan kesopansantunan pesan atau infomasi dalam pembicaraan yang dimaksudkan tidak tersampaikan dengan baik, bahkan terkadang salah penafsiran dalam menerima dan memahami.

Berkenaan dengan hal tersebut salah satu pembelajaran bahasa di sekolah adalah adanya kompetensi keterampilan berbicara dan berbahasa. Kompetensi tersebut terdapat dalam salah satu materi mata pelajaran bahasa Indonesia, salah satu materi yang terkait dengan kompetensi tersebut adalah pembelajaran menulis teks pidato yang ada di kelas IX jenjang SMP.

Sasaran atau objek dalam kajian penelitian ini adalah teks pidato siswa kelas IX SMP Negeri 1 Cidadap. Objek/sasaran itu merupakan pembinaan 


\section{Yanyan \\ ANALISIS KESANTUNAN IMPERATIF BAHASA INDONESIA \\ DALAM TEKS PIDATO SISWA KELAS IX SMP NEGERI 1 CIDADAP KABUPATEN SUKABUMI}

dan pembelajaran berbahasa dalam konteks resmi pada kegiatan proses pembelajaran di sekolah, bentuk kata dan tata bahasa yang digunakan merupakan hal yang dapat dilihat dari segi dan fungsi pembicaraan dalam sebuah pidato. Selain hal tersebut wacana pidato merupakan media atau alat yang dapat digunakan untuk berkomunikasi dan dapat berfungsi untuk menyampaikan maksud atau tujuan tertentu.

Wacana pidato termasuk kedalam kajian pragmatik. Menurut Parker (dalam Rahardi,2005:48) dijelaskan bahwa "pragmatik merupakan cabang ilmu bahasa yang mempelajari struktur bahasa secara eksternal". artinya suatu ilmu yang mempelajari tentang maksud sebuah bahasa yang dipengaruhi oleh situasi ketika berkomunikasi antara penutur dan mitra tutur. Studi pragmatik dikaitkan dengan konteks yang melatarbelakanginya, sedangkan studi bahasa tidak dikaitkan dengan konteks (bebas konteks) artinya tidak dipengaruhi oleh situasi dan kondisi yang melatarbelakanginya.

Objek dalam kajian ini adalah pidato. Ada beberapa jenis pidato, yaitu pidato impromtu, manuskrip, memoriter dan ekstempore. Fokus dalam kajian penelitian ini adalah pidato jenis manuskrip siswa kelas IX SMP Negeri 1 Cidadap. Pidato jenis manuskrip memiliki ciri-ciri sebagai berikut: 1) Dapat menyampaikan arti yang tepat dan pernyataan yang gamblang karena katakatanya dapat dipilih sebaik-baiknya; 2) Teks dapat disusun kembali sehingga pernyataan dapat dihemat; 3) Kata-kata sudah disiapkan oleh karena itu kefasihan bicara dapat dicapai; 4) Halhal yang menyimpang dapat dihindari; 5) Manuskrip dapat diterbitkan atau diperbanyak.

Berdasarkan beberapa hal yang telah dipaparkan tersebut, maka penulis mengadakan penelitian dengan judul "Analisis Kesantunan Imperatif Bahasa Indonesia dalam Teks Pidato Siswa
Kelas IX SMP Negeri 1 Cidadap

Kabupaten Sukabumi Tahun Pelajaran 2019/2020."

\section{METODE PENELITIAN}

Jenis atau metode penelitian yang digunakan dalam penelitian ini adalah jenis kualitatif dengan rancangan deskriptif. Menurut Arikunto (2002:3) menyatakan bahwa "penelitian kualitatif merupakan salah satu penelitian yang hanya semata-mata dilakukan berdasarkan pada fenomena atau fakta yang ada yang memang secara heuristis hidup pada penuturnya”. Penelitian kualitatif adalah menggambarkan, memaparkan atau melukiskan objek berdasarkan fakta-fakta yang tampak sebagaiman adanya dan apa adanya. Hal ini dimaksud sebagai salah satu jenis penelitian yang hasil temuannya tidak dapat diperoleh oleh prosedur penelitian lain seperti statistik atau bentuk-bentuk hitungan lainnya.

Jenis kualitatif ini digunakan atas dasar beberapa faktor yang dilihat ada kesesuaian yang mengaitkan antara bahan atau objek yang akan diteliti dengan ciri-ciri sebagai berikut : (1) Pengumpulan data pada penelitian ini dilakukan secara langsung pada objek yaitu teks pidato siswa yang di dalamnya terdapat penggunaan kalimat imperatif, dengan demikian penelitian ini merupakan penelitian ilmiah. Sedangkan sebagai instrumen dalam penelitian ini adalah peneliti itu sendiri. (2) Penelitian ini didalamnya berisi gambaran atau paparan (deskriptif) tentang bahasa atau kalimat yang didalamnya terdapat konteks makna kesantunan imperatif; (3)Analisis yang dilakukan dalam penelitian ini bersifat induktif; (4)Makna dalam penelitian ini dipandang sebagai sesuatu yang esensial; (Moleong, 2012:4).

Pendekatan yang digunakan dalam penelitian ini adalah pendekatan pragmatik. Pendekatan ini digunakan untuk mengidentifikasi penggunaan bahasa Indonesia yang menunjukan 


\section{Yanyan \\ ANALISIS KESANTUNAN IMPERATIF BAHASA INDONESIA \\ DALAM TEKS PIDATO SISWA KELAS IX SMP NEGERI 1 CIDADAP \\ KABUPATEN SUKABUMI}

kesantunan imperatif ajakan, permintaan dan suruhan dalam teks pidato siswa kelas IX SMP Negeri 1 Cidadap.

Berdasarkan pendekatan dan jenis penelitian inilah penulis akan meneliti kesantunan imperatif bahasa Indonesia dalam teks pidato yang ditulis oleh siswa kelas IX SMP Negeri 1 Cidadap. Naskah pidato tersebut digunakan untuk mengidentifikasi kemudiaan di mendeskripsikan kesantunan imperatif yang terdapat dalam teks pidato tersebut.

\section{HASIL PENELITIAN DAN PEMBAHASAN}

\section{A. Hasil Penelitian}

Berdasarkan hasil penelitian dan analisis yang dilakukan data yang diperoleh sebagai berikut: Dari sepuluh teks pidato yang dianalisis mengasilkan data sebanyak 21 data yang terdiri dari 13 (tiga belas) data yang menunjukan penggunaan kalimat kesantunan imperatif ajakan, 7 (tujuh) data yang menunjukan penggunaan kalimat kesantunan imperatif permintaan, dan 1 (satu) data yang menunjukan penggunaan kalimat kesantunan imperatif suruhan.

\section{Kalimat Kesantunan Imperatif Ajakan}

(1) Pertama marilah kita panjatkan puji syukur kehadirat allah Swt yang telah melimpahkan nikmat nya. Sholawat dan salam semoga tercurahkan kepada baginda alam yakni habibana wanabiyana Muhammad SAW.

(Sumber data No.1: Abizar Putra Pradipta,2020)

\section{Informasi Indeksal:}

Pembicara mengawali pidatonya mengajak kepadaseluruh pendengar untuk sama-sama memanjatkan puji dan syukur kepada Allah Swt dan bersolawat kepada Nabi Muhammad SAW.
(2) Hendaknya mari kita bisa membentengi dirikita dengan agama memperkuat ketaqwaan tehadap Allah Swt agar terhindar dan tidak terjerumus kedalam bahaya narkoba.

(Sumber data No.1: Abizar Putra Pradipta,2020)

\section{Informasi Indeksal:}

Pembicara dalam pidatonya mengajak kepada pendengar untuk sama-sama menjauhi narkoba dengan cara membentengi diri dengan agama serta meningkatkan keimanan kepada Allah Swt agar tidak tergiur dan terjerumus kedalam narkoba

(3) Mari kita lihat jumlah pengguna narkoba di Indonesia setiap waktunya semakin bertambah dan semakin begitu besar. Hal tersebut mungkin dikarenakan lemahnya penegakan hukum.

(Sumber data No.1: Abizar Putra Pradipta,2020)

\section{Informasi Indeksal :}

Pembicara dalam pidatonya mengajak kepada pendengar untuk melihat dan memperhatikan bahwa pengguna narkoba di Indonesia dari hari kehari terus bertambah cukup pesat dan hal ini perlu diwaspadai , salah satu penyebabnya dimungkinkan kurang tegasnya aparat penegak hukum dalam menangani kasus narkoba

(4) Penyebaran narkoba juga bisa disebabkan oleh pergaulan yang bebas, dan itulah sebabnya pengguna narkoba saat ini semakin meningkat oleh karena itu marilah kita menjaga diri kita, keluarga kita dan lingkungan kita dari jeratan narkoba dan jangan ada ruang serta jalan untuk masuknya barang haram tersebut.

(Sumber data No.2: Adeliano Setiawan, 2020)

Informasi Indeksal : 


\section{Yanyan \\ ANALISIS KESANTUNAN IMPERATIF BAHASA INDONESIA \\ DALAM TEKS PIDATO SISWA KELAS IX SMP NEGERI 1 CIDADAP \\ KABUPATEN SUKABUMI}

Pidato yang disampaikan ini mengajak kepada pendengar agar menjauhi dan menjaga diri, keluarga serta lingkungan jangan sampai rusak karena narkoba dan tidak membiarkan adanya celah atau jalan untuk masuknya narkoba.

(5) Dengan narkoba kejahatan akan meningkat dan kemaksiatan akan merajalela oleh karena itu kita harus terus mengawasi keluarga kita jangan sampai terjerumus narkoba dan terus aktif dalam pemberantasan narkoba.

(Sumber data No. 3 : Denda Ridika Putri , 2020) Informasi Indeksal:

Pembicara dalam pidatonya mengajak kepada pendengar untuk mengetahui bahaya narkoba dan senantiasa mengawasi dan menjaga keluarga masing-masing serta terus aktif dalam memberantas narkoba.

(6) Untuk itu marilah kita hindari dan jauhi narkoba..

(Sumber data No.3 : Denda Ridika Putri , 2020)

Informasi Indeksal:

Pembicara mengajak kepada pendengar untuk menghindari dan menjauhi narkoba.

(7) Marilah kita panjatkan puji syukur kita kepada Allah Swt,yang telah memberikan nikmatnya kepada kita semua sehingga kita bisa berkumpul disini dengan keadaan sehat walafiat.

(Sumber data No.4 : Linda Ariyanti , 2020)

\section{Informasi Indeksal:}

Pembicara mengajak kepada pendengar untuk besyukur kepada Allah atas segala nikmat yang telah diberikan salah satunya adalah kesehatan, sehingga pendengar dan pembicara dapat berkumpul pada kesempatan itu.

(8) Oleh karena itu mari kita sebagai generasi muda hindari dan janganlah sesekali menggunakan atau mengonsumsi yang namanya narkoba.

(Sumber data No.4 : Linda Ariyanti , 2020 )

\section{Informasi Indeksal:}

Pembicara mengajak kepada pendengar khususnya kepada para generasi muda untuk menghindari narkoba dan janganlah untuk mencobanya jadilah generasi muda anti narkoba

(9) Marilah kita hindari serta ikut memberantas narkoba.

(Sumber data No.5 : Merlan , 2020)

\section{Informasi Indeksal :}

Pembicara mengajak kepada pendengar untuk menghindari narkoba dan ikut aktif dalam pemberantasan narkoba.

(10) Mari kita jauhi narkoba musuh kita bersama.

(Sumber data No.8 : Muhamad Rizal , 2020)

\section{Informasi Indeksal :}

Pembicara mengajak kepada pendengar dengan tegas untuk menjauhi narkoba dan menegaskan bahwa narkoba adalah musuh bersama.

(11) Saya mencoba menyimpulkan bahwa kita perlu menyadari bersama bahwa narkoba sangat berbahaya bagi generasi muda kita, anak-anak kita bahkan cucu kita nanti semuanya akan rusak .angka kejahatan dan kemaksiatan akan meningkat dan ini akan menjadi kekhawatiran kita semua mari kita jaga dan berantas sejak dini.

(Sumber data No.9 :Susanti , 2020)

\section{Informasi Indeksal :}

Pembicara mengajak kepada pendengar untuk mengetahui bahaya narkoba dan senantiasa mengawasi dan menjaga keluarga masing-masing dari bahaya narkoba yang merusak dan berpartisipasi dalam pemberantasan narkoba.

(12) Disini saya ingin menyampaikan narkoba sangat berbahaya , 


\section{Yanyan \\ ANALISIS KESANTUNAN IMPERATIF BAHASA INDONESIA \\ DALAM TEKS PIDATO SISWA KELAS IX SMP NEGERI 1 CIDADAP \\ KABUPATEN SUKABUMI}

narkoba bisa merusak kehidupan kita, serta menghancurkan masa depan kita dengan narkoba kita akan merasa ketagihan dan sulit untuk meninggalkannya .kesehatan fisik kita akan terganggu dan juga mental kita akan rusak oleh karena itu mari kita kta jauhi narkoba.

(Sumber data No.10:Yuni Rahmawati , 2020)

\section{Informasi Indeksal :}

Pembicara meminta kepada pendengar, agar menjauhi narkoba karena narkoba merusak segalanya.

(13) Mari kita jauhi narkoba dan jangan sampai kita menjadi korbannya.

(Sumber data No.10 :Yuni Rahmawati , 2020)

Informasi Indeksal :

Pembicara mengajak kepada pendengar, agar menjauhi narkoba dan jangan pernah jadi korban narkoba.

Dari hasil analisis yang dilakukan, ada beberapa kalimat imperatif ajakan yang peneliti temukan dengan penanda kesantunan mari . Dengan demikian teks pidato siswa kelas IX SMP Negeri 1 Cidadap menunjukan kesantunan.

\section{Kalimat Kesantunan Imperatif Permintaan}

(14) Yang dapat kita lakukan dalam memberantas narkoba antara lain awasi pergaulan anak remaja kita, beri kesibukan dengan kegiatan yang positif, berikan informasi pada yang berwajib apabila terdapat kegiatan yang mencurigakan dan beri pengetahuan agama karena dengan keimanan yang kuat maka kita akan terhindar dari godaan bahaya narkoba.

(Sumber data No.5 : Merlan, 2020)

\section{Informasi Indeksal :}

Pembicara meminta kepada pendengar untuk selalu waspada dan melakukan beberapa langkah antisifasi agar terhindar dari narkoba .

(15) Dalam hal ini pemerintah khususnya penegak hukum diharapkan lebih tegas dalam mencegah pengedaran narkoba serta menindak tegas bandar-bandar narkoba dengan menghukum dengan seberat-beratnya.

(Sumber data No.5 : Novan Ramadhan Putra, 2020)

Informasi Indeksal :

Pembicara meminta kepada pendengar, khususnya pemerintah untuk lebih serius dalam menindak dan memberantas narkoba.

(16) Dan jadilah generasi muda yang anti narkoba dan aktif dalam memberantas narkoba.

(Sumber data No.2 : Adeliano Setiawan, 2020)

Informasi Indeksal :

Pembicara meminta dan memberi tahu dengan tegas kepada pendengar khususnya generasi muda untuk menjadi generasi muda yang terbebas dari narkoba dan anti narkoba serta aktif dalam memberantas pengedaran narkoba.

(17) Disni saya ingin menyampaikan bahwa narkoba adalah sesuatu hal yang sangat berbahaya oleh karena itu jauhilah narkoba, dengan narkoba bukan hanya fisik dan juga mental yang rusak tetapi masa depan pun akan hilang oleh sebab itu jauhi narkoba karena merusak segalanya.

(Sumber data No.7 : Novi Lestari, 2020)

\section{Informasi Indeksal:}

Pembicara meminta kepada pendengar, agar menjauhi narkoba karena narkoba merusak segalanya.

(18) Jadi saya harap para orangtua senentiasa memperhatikan pergaulan anaknya-anaknya karea narkoba tidak memandang anak-anak,dewasa ataupun orang yang bisa dikatakan tua sebagai korbannya. 


\section{Yanyan \\ ANALISIS KESANTUNAN IMPERATIF BAHASA INDONESIA \\ DALAM TEKS PIDATO SISWA KELAS IX SMP NEGERI 1 CIDADAP \\ KABUPATEN SUKABUMI}

(Sumber data No.7 : Novi Lestari, 2020)

\section{Informasi Indeksal:}

Pembicara meminta kepada pendengar, agar senantiasa mengawasi dan memperhatikan anak remajanya dalam bergaul jangan sampai jadi sasaran pengedaran narkoba yang akhirnya terjerumus dan menjadi korban narkoba.

(19) Saya mohon maaf yang sebesarbesarnya apabila ada perkataan yang kurang tepat dihadapan hadirin semuanya, sekian dan terimakasih.

(Sumber data No.7 : Novi Lestari, 2020)

\section{Informasi Indeksal:}

Pembicara dalam akhir pembicaraannya meminta maaf kepada pendengar, apabila ada hal perkataan yang kurang tepat yang telah disampaikan sebelumnya.

(20) Pengguna narkoba asanya didominasi oleh kaum remaja .oleh karena itu tolong antisipasi sejak dini jangan sampai narkoba terus merajalela.

(Sumber data No.8 : muhamad Rizal, 2020)

\section{Informasi Indeksal:}

Pembicara dalam akhir pembicaraannya meminta maaf kepada pendengar, apabila ada hal perkataan yang kurang tepat yang telah disampaikan sebelumnya.

Dari hasil analisis yang dilakukan pada teks pidato siswa, peneliti menemukan beberapa kalimat imperatif permintaan dengan menggunakan penanda kesantunan harap, mohon dan tolong serta prasa lain yang bermakna minta. Dengan demikian maka teks pidato siswa kelas IX SMP Negeri 1 Cidadap dianggap telah menunjukan kesantunan.

\section{Kalimat Kesantunan Imperatif Suruhan}

(21) coba kita perhatikan dan awasi anak-anak kita jangan sampai bergaul bebas dan akhirnya mengenal narkoba ,karena narkoba tidak akan mengenal usia ataupun golongan untuk menjadi mangsannya.

(Sumber data No.6 : Novan Ramadhan Putra,2020)

\section{Informasi Indeksal :}

Pembicara menyuruh kepada pendengar agar mengawasi anak-anaknya dalam pergaulan jangan sampai terlibat dan menjadi pengguna narkoba karena narkoba tidak mengenal batasan usia untuk menjadi korbannya.

Hasil dari analisis yang dilakukan pada teks pidato siswa, peneliti menemukan kalimat imperatif suruhan dengan menggunakan penanda kesantunan coba. Dengan demikian teks pidato siswa kelas IX SMP Negeri 1 Cidadap dianggap telah menunjukan kesantunan.

\section{B. Pembahasan}

Sebagaimana halnya yang dikemukakan Parker (dalam Rahardi,2005:48) bahwa "pragmatik merupakan cabang ilmu bahasa yang mempelajari struktur bahasa secara eksternal". artinya suatu ilmu yang mempelajari tentang maksud sebuah bahasa yang dipengaruhi oleh situasi ketika berkomunikasi antara penutur dan mitra tutur. Studi pragmatik dikaitkan dengan konteks yang melatarbelakanginya, sedangkan studi bahasa tidak dikaitkan dengan konteks (bebas konteks) artinya tidak dipengaruhi oleh situasi dan kondisi yang melatarbelakanginya. Dengan demikian studi ini lebih berhubungan dengan analisis makna atau maksud yang disampaikan penutur (penulis) dan ditafsirkan oleh pendengar (pembaca).

Berkaitan dengan hal tersebut penelitian ini fokus pada analisis makna tuturan dalam teks pidato siswa kelas IX SMP Negeri 1 Cidadap.Penganalisisan di batasi hanya 3 hal, yaitu kalimat kesantunan imperatif ajakan, kalimat 


\section{Yanyan \\ ANALISIS KESANTUNAN IMPERATIF BAHASA INDONESIA \\ DALAM TEKS PIDATO SISWA KELAS IX SMP NEGERI 1 CIDADAP \\ KABUPATEN SUKABUMI}

kesantunan imperatif permintaan dan kalimat kesantunan imperatif suruhan.

\section{Kalimat kesantunan Imperatif ajakan}

Kalimat

kesantunan

imperatif Ajakan biasanya ditandai dengan kata penanda kesantunan sebagai berikut: 1) hendaklah, 2) mari, 3) coba, 4) biar, 5) harap, 6) hendaknya, 7) ayo. Berdasarkan hasil penelitian terhadap teks pidato siswa terdapat 13 data kalimat yang menujukan kesantunan imperatif ajakan.

Jumlah kalimat imperatif ajakan ternyata paling banyak digunakan oleh siswa yaitu dengan penanda kesantunan mari dibandingkan dengan kesantunan imperatif permintaan dan suruhan. Dari 21 data yang dianalisis 13 data menunjukan kesantunan imperatif ajakan.

2. Kalimat Kesantunan Imperatif Permintaan

Kalimat kesantunan imperatif permintaan adalah kalimat yang kadar susruhannya sangat halus . Lazimnya kalimat imperatif permintaan disertai dengan sikap penutur yang merendah dibandingkan dengan sikap penutur pada saat menuturkan kalimat imperatif biasa. Kalimat kesantunan imperatif permintaan biasanya menggunakan kata-kata berupa penanda kesantunan antara lain: tolong, coba, harap, sudilah kiranya, dapatkah, seandainya, diminta dengan hormat, dan dimohon dengan sangat.

Dari hasil analisis yang dilakukan pada teks pidato siswa, peneliti menemukan 7 (tujuh) data dari 13 data yang dianalisis menunjukan kalimat imperatif permintaan dengan menggunakan penanda kesantunan harap, mohon dan tolong serta prasa lain yang bermakna minta.

\section{Kalimat kesantunan Imperatif Suruhan}

Beberapa kata yang peneliti jadikan kriteria sebagai penanda kesantunan imperatif suruhan yaitu: silakan, ayo, hendaklah biar, coba, harap, hendaknya, mohon, dan tolong.

Hasil dari analisis yang dilakukan pada teks pidato siswa, peneliti menemukan 1 (satu) dari 21 data yang dianalisis merupakan kalimat imperatif suruhan dengan menggunakan penanda kesantunan coba. Dengan demikian teks pidato siswa kelas IX SMP Negeri 1 Cidadap dianggap telah menunjukan kalimat kesantunan imperatif suruhan.

\section{KESIMPULAN}

Berdasarkan hasil penelitian yang dilakukan dapat disimpulkan bahwa siswa kelas IX SMP Negeri 1 Cidadap dalam menulis teks pidato lebih banyak menggunakan kalimat kesantunan imperatif ajakan dibandingkan dengan kalimat kesantunan imperatif permintaan dan kalimat kesantunan imperatif suruhan.

Hasil penelitian menemukan dari sepuluh teks pidato yang dianalisis dan diperoleh 21(dua puluh satu) data, 13 (tiga belas) data menunjukan penggunaan kalimat kesantunan imperatif ajakan sedangkan sebanyak 7 (tujuh) data menunjukan kalimat kesantunan imperatif permintaan serta hanya 1 (satu) data lagi menunjukan kalimat kesantunan imperatif suruhan.

\section{SARAN}

Bertitik tolak dari kesimpulan hasil penelitian dan pembahasan, peneliti menyarankan beberapa hal yang berkaitan dengan pembelajaran kesantunan di SMP Negeri 1 Cidadap Kabupaten Sukabumi, yaitu: 


\section{Yanyan \\ ANALISIS KESANTUNAN IMPERATIF BAHASA INDONESIA \\ DALAM TEKS PIDATO SISWA KELAS IX SMP NEGERI 1 CIDADAP \\ KABUPATEN SUKABUMI}

1. Melalui proses pembelajaran bahasa Indonesia guru mampu meningkatkan kompetensi siswa dalam membuat teks pidato;

2. Berkaitan dengan kesantunan imperatif, guru dapat mengenalkan jenis kesantunan imperatif dalam bahasa Indonesia di dalam proses pembelajaran khusunya dalam membuat teks pidato.

3. Peneliti menyarankan agar guru tidak hanya menerapkan kesantunan imperatif bahasa Indonesia dalam penulisan teks pidato saja, tetapi juga dapat diterapkan dalam kegiatan komunikasi sehari-hari.

\section{DAFTAR PUSTAKA}

Arikunto, Suharsimi. 2002. Prosedur Penelitian Suatu Pendekatan Praktik. Jakarta: Rineka Cipta.

Brown, Gilian, dan George Yule. 1996. Analisis Wacana. Jakarta: PT Graha Media Pustaka Umum.

Hendrikus, Dori Wuwur.20 Terampil Berpidato,

Berdiskusi,Berargumentasi dan Bernegosiasi. Yogyakarta

:Kanisius.

Leech, Geoffrey. 1993. Prinsip-prinsip Pragmatik. Jakarta: Universitas Indonesia Press.

Moleong, Lexy J. 2012. Metodologi Penelitian Kualitatif (Edisi Revisi). Bandung: PT. Remaja Rosdakarya.

Miles dan Huberman. 1992. Model Analisis Data. Bandung: Tarsito.

Rahardi, R. Kunjana. 2005. Pragmatik Kesantunan Imperatif Bahasa Indonesia Jakarta: Erlangga.

Rakhmat,Jalaludin.2008.Retorika Mode rn Pendekatan Praktis.Bandung: PT Remaja Rosdakarya. 